\title{
Nicotinamide Attenuates Streptozotocin-Induced Diabetes Complications and Increases Survival Rate in Rats: Role of Autonomic Nervous System.
}

\section{Paula Lázara Cruz}

University of São Paulo Medical School - InCor https://orcid.org/0000-0001-9917-9570

Ivana Cinthya Moraes-Silva

University of São Paulo Medical School - InCor

Amanda Aparecida Ribeiro

University of São Paulo Medical School-InCor

Jacqueline Freire Machi

University of Miami - Department of Molecular and Cellular Pharmacology

Marcelo Dantas Tavares Melo

University of São Paulo Medical School - InCor

Fernando dos Santos

University of California - Department of Anesthesiology

Maikon Barbosa da Silva

University of São Paulo Medical School -InCor

Celia Maria Cassaro Strunz

University of São Paulo Medical School - InCor

Elia Garcia Caldini

University of São Paulo Medical School -Department of Pathology

Maria Cláudia C Irigoyen ( $\square$ hipirigoyen@incor.usp.br)

University of São Paulo Medical School - InCor https://orcid.org/0000-0003-2097-3662

\section{Research}

Keywords: nicotinamide, diabetes, autonomic nervous system

Posted Date: September 18th, 2020

DOI: https://doi.org/10.21203/rs.3.rs-72324/v1

License: (a) (1) This work is licensed under a Creative Commons Attribution 4.0 International License.

Read Full License 


\section{Abstract}

Background: Diabetes induced by streptozotocin (STZ) is a well-known model to study diabetes complications in rats and mice. The association of nicotinamide $(\mathrm{N})$ with STZ has been widely used, and the severity of diabetes is attenuated. However, the mechanisms supporting this attenuation are not completely understood. Considering the key role of the autonomic nervous system in the pathophysiology of several diseases, we hypothesized that $\mathrm{N}$ could affect baroreflex sensitivity and autonomic modulation, thus protecting from the aggressive effects of STZ.

Methods: Male Wistar rats were divided into control (C) and STZ-induced diabetes (D). Half of the rats from each group received a single dose of $\mathrm{N}(100 \mathrm{mg} / \mathrm{Kg})$ before STZ injection (CN and DN). All groups were followed-up for 5 weeks.

Results: Body weight loss of more than $40 \%$ was observed in D throughout the period (D: $271.00 \pm 12.74$ g; DN: $344.62 \pm 17.82)$. Increased glycemia was seen in D rats $(541.28 \pm 18.68 \mathrm{mg} / \mathrm{dl})$ while DN group had a slight decrease $(440.87 \pm 20.96 \mathrm{mg} / \mathrm{dl})$. However, insulin resistance was observed only in $\mathrm{D}$. In relation to C, heart rate, mean blood pressure and diastolic function were reduced when compared to $D$, together with parasympathetic modulation (RMSSD D: $5.4 \pm 0.2 \mathrm{~ms}$ and $\mathrm{DN}: 9.3 \pm 1.2 \mathrm{~ms}$ ) and baroreflex sensitivity. All of these parameters were improved in DN when compared to $\mathrm{D}$. Improved baroreflex sensitivity and parasympathetic modulation were correlated with glycemia, insulin resistance, and body weight mass. Additionally, DN group increased survival rate.

Conclusions: These results suggest that the association of nicotinamide in STZ-induced diabetic rats prevents most of the expected derangements mainly by preserving parasympathetic and baroreflex parameters.

\section{Background}

Diabetes mellitus (DM) is a complex metabolic disease affecting about 422 million people worldwide. It is characterized by chronic hyperglycemia, insulin resistance, and/or insulin secondary deficiency caused by the failure of $\beta$-pancreatic cells $[1,2]$.

According to the classification proposed by the American Diabetes Association (ADA), there are two DM types: type 1 diabetes and type 2 diabetes are heterogeneous diseases in which clinical presentation and disease progression may vary considerably [1]. Type 1 diabetes is usually diagnosed in children and adolescents. It is an autoimmune disease characterized by the destruction of $\beta$-pancreatic cells by lymphocytes and macrophages resulting in hyperglycemia, usually leading to absolute insulin deficiency [3]. Type 2 diabetes, which accounts for $90-95 \%$ of all cases of DM, occurs due to a progressive loss of $\beta$ cell insulin secretion frequently on the background of insulin resistance compensated by increased secretion of insulin [1, 2]. However, this prolonged overstimulation of insulin secretion leads to progressive exhaustion and degradation of $\beta$-cells $[4,5]$. Multiple risk factors for type $2 \mathrm{DM}$ are associated 
with bad eating habits, increased adiposity and sedentarism, leading to the hypothesis that type II DM is a result of gene-environment interactions [6, 7].

Different experimental models emerged as possibilities to mimic human types 1 and 2 DM to study its development and complications. Masiello et al. (1998) developed a rat model of diabetes induced by administration of streptozotocin (STZ) and nicotinamide (N). STZ selectively destroys pancreatic beta cells, while $\mathrm{N}$ decrease the damage caused by $\mathrm{STZ}$, creating a state of partial insulin deficiency, similar to what occurs in type 2 diabetes. The severity of STZ $+\mathrm{N}$-induced diabetes is much lower than that of diabetes induced by STZ alone; rats manifest moderate hyperglycemia and do not require exogenous insulin to survive [8]. Type $2 \mathrm{DM}$ is probably to be as elaborate and heterogeneous as the human condition. Thus, in some animals, insulin resistance predominates, while in others there are predominance of $\beta$-cell failure. Models where glucose intolerance is part of a large phenotype, such as: obesity, dyslipidaemia and hypertension may also provide valuable insights into human type 2 DM [9].

$\mathrm{N}$, a derivative of vitamin B3, effectively protects $\beta$-cells against the cytotoxicity of STZ. The protective action of $\mathrm{N}$ relies on the decreased damage and DNA-methylation in pancreatic islets, improved insulin secretion [10, 11], neuroprotection and antioxidant functions [12].

Although all of these mechanisms play a pivotal role in diabetes development, autonomic nervous system also underlies cardiometabolic pathophysiology in metabolic diseases. Studies in fructose-fed animals demonstrated that autonomic nervous system dysfunction, mainly represented by baroreflex sensitivity impairment, not only accompanies the disease progression but may also precede metabolic and hemodynamics alterations $[13,14]$. Lin et al. (2008) showed early cardiac autonomic dysfunction and baroreflex impairment in diabetic rats pre-treated with $\mathrm{N}$; however, rats were anesthetized during the evaluation [15]. In young adults with diabetic parents compared to non-diabetic parents, autonomic alterations were observed despite differences in baseline glycemia levels [16].

Since autonomic control of circulation seems to modulate DM complications, and $\mathrm{N}$ presents a protective role in diabetic rats induced by STZ, we hypothesized that preserved cardiovascular autonomic modulation and baroreflex sensitivity could also mediate the attenuation of STZ-induced derangements in rats pre-treated with $\mathrm{N}$. Therefore, this study aimed to evaluate the effect of $\mathrm{N}$ prior to STZ-induced diabetes in baroreflex sensitivity and cardiovascular autonomic modulation, and its association with hemodynamics and metabolic parameters.

\section{Methods}

\section{Animals and groups}

All experimental procedures were approved by the Ethics Committee for Animal Experimentation from the University of São Paulo Medical School (protocol no. 338/12). This investigation was conducted in accordance with the Guide for the Care and Use of Laboratory Animals published by the U.S. National Institutes of Health. Male Wistar rats (330-390 g) were housed in collective polycarbonate cages (four 
animals per cage) with a controlled temperature $\left(22^{\circ} \mathrm{C}\right)$ and a 12:12-h light-dark cycle. Rats were randomly divided into 4 four groups (6-8 rats/group): control (C), diabetic (D), control pre-treated with nicotinamide (CN), and diabetic pre-treated with nicotinamide (DN).

\section{Nicotinamide treatment and diabetes induction}

On the day of diabetes induction, all rats underwent a 6-hour fasting. CN and DN rats received a single intraperitoneal injection of $100 \mathrm{mg} / \mathrm{kg}$ of nicotinamide (Sigma-Aldrich) $15 \mathrm{~min}$ before diabetes induction $[17,18]$. D and DN rats were made diabetic by a single injection of freshly prepared STZ $(50 \mathrm{mg} / \mathrm{kg}$ body weight) in citrate buffer (0.1 M, pH 4.5) in the tail vein [19]. Control animals received an intraperitoneal injection of $\mathrm{NaCl} 0.9 \%$ and citrate buffer without STZ. After 15 days of induction, glycemia was measured and only animals with levels higher than $180 \mathrm{mg} / \mathrm{dl}$ were included in the study. All groups were followedup for 5 weeks.

\section{Body weight and Lee index}

All animals were weighed once per week throughout the protocol period. To determine the body mass index, Lee index was calculated by cube root of body weight $(\mathrm{g}) \times 10$ /naso-anal length $(\mathrm{mm})[20,21]$.

\section{Glycemia and triglycerides measurements}

At the beginning and at the end of the protocol, all animals underwent 4 hours of fasting. A drop of blood from the tail vein was collected to measure plasma glucose using a glucometer, and another drop was collected for triglyceride measurement with Accu-Chek e Accutrend GTC (Hoffman-La Roche Ltd, IN, EUA), respectively.

\section{Insulin tolerance test (ITT)}

ITT was performed at the end of the protocol. Baseline glucose levels were determined according to Furuya et al. 2003. Insulin (0.75 units $/ \mathrm{kg}$ ) was injected subcutaneously. Then, blood samples were collected from the tail vein at 0 (just before the insulin injection), 4, 8, 12 and 16 min (after the insulin injection) for the glucose assay. Plasma glucose was measured from blood samples collected from the tail vein with the use of a glucometer (Accu-Check; Hoffman-La Roche Ltd.) [22-24]. Glycemia values for 4 to 16 minutes were used to calculate the constant decrease of plasma glucose (kITT) [25].

\section{Echocardiographic evaluations}

Echocardiographic evaluations were blindly performed by an expert and in accordance to the guidelines of the American Society of Echocardiography. Rats were anaesthetized $(50 \mathrm{mg} / \mathrm{kg}$ ketamine and $12 \mathrm{mg} / \mathrm{kg}$ xylazine, intraperitoneal injection) and images were obtained with a $10-14 \mathrm{mHz}$ linear transducer in a SEQUOIA 512 (ACUSON Corporation, Mountain View, CA, USA) for measurements of left ventricular function and morphology. Echocardiographic parameters were measured as previously described in detail elsewhere $[26,27]$.

\section{Hemodynamics and baroreflex sensitivity}


One day after the echocardiographic evaluation, two polyethylene catheters filled with $0.06 \mathrm{ml}$ of saline were implanted into the femoral artery and femoral vein (PE-10). Rats were anesthetized with isoflurane (1 a $2.5 \%$ ), for direct measurements of arterial pressure and drug administration, respectively. After this procedure, the animals were allowed to recover in individual cages. The rats were taken to the recording room at least $30 \mathrm{~min}$ before the beginning of the experiment, and a quiet environment was maintained to avoid any stress. On the next day, the arterial cannula was connected to a strain-gauge transducer (Blood Pressure XDCR; Kent Scientific, Torrington, CT), and arterial pressure signals and pulse interval (heart rate) were digitally recorded over a 30-minute period in conscious animals, moving freely during the experiments using a data acquisition system (WinDaq, $2 \mathrm{kHz}$, DATAQ, Springfield, OH, USA) as previously described $[20,28]$. Beat-by-beat time series of systolic, diastolic, and mean arterial pressures were generated. Heart rate was measured from successive diastolic pulse intervals. This basal acquisition was used to evaluate heart rate variability and systolic arterial pressure variability.

For baroreflex sensitivity evaluation, sequential bolus injections of increasing doses of phenylephrine $(0.25$ to $32 \mu \mathrm{g} / \mathrm{kg})$ and sodium nitroprusside $(0.05$ to $1.6 \mu \mathrm{g} / \mathrm{kg})$ were given to increases or decreases in mean arterial pressure responses (for each drug), ranging from 5 to $40 \mathrm{mmHg}$.32. Peak increases or decreases in mean arterial pressure after phenylephrine or sodium nitroprusside injection and the corresponding peak reflex changes in heart rate were recorded for each dose of the drug. A 3-5 min interval between doses was necessary for arterial pressure to return to baseline. Baroreflex sensitivity was expressed as bradycardic response and tachycardic response, expressed as $\mathrm{bpm} / \mathrm{mmHg}$, as described elsewhere in beats per minute per millimeter of mercury $[26,28,29]$. After the hemodynamic recordings, rats were euthanized by decapitation. The heart, pancreas and gastrocnemius were rapidly removed, rinsed in ice-cold $0.9 \% \mathrm{NaCl}$ solution and weighed.

\section{Heart rate variability}

The heart rate variability was performed by linear methods in time and frequency domain by Cardioseries ${ }^{\circledR}$ v2.4. Temporal series of pulse interval and systolic blood pressure from baseline recordings were analyzed and total heart rate variability (HRV) and systolic arterial pressure variability (SAPV) were calculated. The mean square root of differences between consecutives PI (RMSSD), an index of parasympathetic modulation in time domain, was also evaluated. For frequency domain, the interpolated wave of these same basal periods were divided in segments of 512 beats with overlap of $50 \%$ and processed by Fast Fourier Transform. One spectrum was obtained by each segment and the oscillatory components were quantified in low frequency (LF; 0.20 to $0.75 \mathrm{~Hz}$ ), which indicates sympathetic modulation predominance, and high frequency ( $\mathrm{HF}, 0.75$ to $3.00 \mathrm{~Hz})$, which indicates parasympathetic modulation predominance [30].

\section{Statistical analysis}

All data are expressed as mean \pm SEM. The two-way analysis of variance followed by Newman-Keuls post hoc test was used to compare groups. Repeated measures two-way analysis of variance was used when necessary. Pearson's correlation was used for the study of associations between variables. Kaplan-Meier 
method was used to calculate survival rate and curves were compared by logrank test. Statistical calculations were performed using Graph Pad Prism version 6.0. Significance level was established at $p<$ 0.05 .

\section{Results}

\section{Body weight, Lee index and tissue weight}

At the end of the protocol $\mathrm{C}$ and $\mathrm{CN}$ groups presented body weight gain in relation to initial values. In contrast, D group presented body weight loss throughout the protocol, and nicotinamide prevented body weight loss in diabetic rats (Fig. 1A). Moreover, diabetic rats presented decreased Lee index when compared to other groups, and nicotinamide in diabetic rats reestablished this parameter (Fig. 1B). Both diabetic groups presented reduction in pancreas weight in relation to non-diabetic rats $(p<0.05)(C: 1.48 \pm$ $0.11 \mathrm{~g} ; \mathrm{CN}: 1.86 \pm 0.21 \mathrm{~g} ; \mathrm{D}: 1.23 \pm 0.06 \mathrm{~g}$; DN:1.11 $\pm 0.07 \mathrm{~g}$ ). Similarly, gastrocnemius muscle weight was also lower in diabetic groups ( $D$ and $D N ; 1.16 \pm 0.10 \mathrm{~g}$ and $1.51 \pm 0.11 \mathrm{~g}$, respectively) when compared to controls ( $C$ and $C N ; 2.29 \pm 0.19$ and $2.04 \pm 0.26 \mathrm{~g}$, respectively). Absolute cardiac mass was not different among groups (C:1.50 $\pm 0.05 \mathrm{~g} ; \mathrm{CN}: 1.72 \pm 0.08 \mathrm{~g} ; \mathrm{D}: 1.44 \pm 0.09 \mathrm{~g} ; \mathrm{DN}: 1.34 \pm 0.07 \mathrm{~g}$ ).

\section{Metabolic parameters}

Before induction, all groups had similar glycemia values (week 0) (Fig. 2A). As expected, STZ induced a sharp increase in glycemia (D: $541.28 \pm 18.68 \mathrm{mg} / \mathrm{dl}$ ) when compared to non-diabetic rats, and although nicotinamide reduced glycemia in STZ rats $(440.87 \pm 20.96 \mathrm{mg} / \mathrm{dl})$, these values were still higher than $C$ and $\mathrm{CN}$ groups ( $110.00 \pm 3.48$ and $108.50 \pm 1.52 \mathrm{mg} / \mathrm{dl}$, respectively). Concomitantly, $\mathrm{D}$ rats presented an important deficiency in the insulin tolerance test $(0.21 \pm 0.05 \mathrm{mg} / \mathrm{dl} / \mathrm{min})$, which was totally prevented by nicotinamide, as observed in DN group (2.30 $\pm 0.47 \mathrm{mg} / \mathrm{dl} / \mathrm{min})$ (Fig. 2B). STZ also induced an increase in triglycerides levels $(180.42 \pm 34.70 \mathrm{mg} / \mathrm{dl})$, while nicotinamide in STZ-induced rats attenuated this increase (111.00 $\pm 5.12 \mathrm{mg} / \mathrm{dl})$ (Fig. 2C).

\section{Hemodynamics and cardiovascular autonomic modulation assessments}

Results from hemodynamic and cardiovascular autonomic modulation are presented in Table 1. D rats presented resting bradycardia and decreased mean blood pressure levels when compared to control groups, while DN rats presented heart rate and blood pressure values equivalent to non-diabetic groups. Heart rate and blood pressure variabilities were not different among groups. Despite the absence of significant alterations in the LF component, which represents sympathetic predominance in autonomic modulation, D group presented reduced absolute HF component, indicating parasympathetic impairment. Positive effect of nicotinamide in diabetic rats was observed in parameters of parasympathetic modulation, as absolute HF component and RMSSD. 
Table 1

Hemodynamics and cardiovascular autonomic modulation in control $(\mathrm{C}, \mathrm{n}=8)$, control nicotinamide $(\mathrm{CN}$, $n=7)$, diabetic $(D, n=7)$, and diabetic nicotinamide ( $D N, n=8)$ groups.

\begin{tabular}{|c|c|c|c|c|}
\hline & C & $\mathrm{CN}$ & D & DN \\
\hline Heart rate (bpm) & $338 \pm 6$ & $343 \pm 6$ & $255 \pm 6^{*^{\dagger}}$ & $299 \pm 10^{\#}$ \\
\hline $\begin{array}{l}\text { Mean blood pressure } \\
(\mathrm{mmHg})\end{array}$ & $110 \pm 2$ & $115 \pm 2$ & $94 \pm 3^{*+}$ & $101 \pm 2^{\#}$ \\
\hline $\mathrm{HRV}\left(\mathrm{ms}^{2}\right)$ & $105.1 \pm 15.5$ & $101.4 \pm 17.6$ & $129.6 \pm 28.9$ & $120.9 \pm 17.7$ \\
\hline RMSSD (ms) & $4.8 \pm 0.3$ & $6.7 \pm 0.6$ & $5.4 \pm 0.2$ & $9.3 \pm 1.2^{\star \#}$ \\
\hline $\mathrm{LF}\left(\mathrm{ms}^{2}\right)$ & $4.5 \pm 0.7$ & $4.2 \pm 1.0$ & $3.6 \pm 0.8$ & $5.2 \pm 0.7$ \\
\hline $\mathrm{HF}\left(\mathrm{ms}^{2}\right)$ & $13.0 \pm 0.8$ & $13.8 \pm 2.2$ & $7.0 \pm 1.2^{\star \star}$ & $13.7 \pm 1.6^{\#}$ \\
\hline LF (n.u.) & $22.8 \pm 2.8$ & $19.8 \pm 3.3$ & $25.6 \pm 3.7$ & $23.5 \pm 2.4$ \\
\hline HF (n.u.) & $77.1 \pm 2.8$ & $80.1 \pm 3.3$ & $71.2 \pm 3.7$ & $76.5 \pm 2.4$ \\
\hline LF/HF & $0.30 \pm 0.04$ & $0.30 \pm 0.05$ & $0.46 \pm 0.04$ & $0.36 \pm 0.04$ \\
\hline SAPV $\left(m m H^{2}\right)$ & $43.9 \pm 1.8$ & $42.2 \pm 4.8$ & $21.8 \pm 10.0$ & $33.1 \pm 3.8$ \\
\hline \multicolumn{5}{|c|}{$\begin{array}{l}\text { Heart rate variability (HRV) and systolic arterial pressure variability (SAPV) computed from } 0.20 \text { to } \\
3 \mathrm{~Hz} \text { (total power), low-frequency (LF: } 0.20-0.75 \mathrm{~Hz} \text { ) and high-frequency (HF: } 0.75-3 \mathrm{~Hz} \text { ) bands; } \\
\text { RMSSD, root mean square of successive differences; n.u., normalized units. }{ }^{*} \mathrm{p}<0.05 \text { vs. } \mathrm{C} \text {; }{ }^{\#} p<0.05 \\
\text { vs. } \mathrm{D},{ }^{\dagger} \mathrm{p}<0.05 \text { vs. CN. }\end{array}$} \\
\hline
\end{tabular}

\section{Baroreflex}

Results of baroreflex sensitivity evaluated by heart rate changes to vasoactive drugs revealed a reflex impairment of the bradycardic response in D vs. C. Nicotinamide treatment in STZ rats increased both tachycardic and bradycardic responses in relation to D (Fig. 3).

\section{Cardiac morphometry and function}

Echocardiography analysis results are shown in Table 2. Left ventricular diameter during systole was not different among groups; however, left ventricular diameter in diastole was diminished in D rats vs. C. Diabetes did not interfere in interventricular septum thickness in diastole, in posterior wall in diastole, and in relative wall thickness. Functional left ventricular analysis revealed diastolic dysfunction with preserved ejection fraction in $D$ rats. Isovolumetric relaxation time was higher in $D$ group in relation to $C$ group, and DN rats showed lower values than $\mathrm{D}$. The ratio between $\mathrm{E}$ wave (early diastolic transmitral flow velocity) and isovolumetric relaxation time (E/IVRT), which was reduced in $D$ group, was similar to $C$ in DN group. No differences in systolic function parameters were observed among groups. 
Table 2

Echocardiographic measurements in the left ventricle of $(C, n=8)$, control nicotinamide $(C N, n=7)$, diabetic ( $D, n=7)$, and diabetic nicotinamide (DN, $n=8)$ groups.

\begin{tabular}{|c|c|c|c|c|}
\hline & $\mathrm{C}$ & $\mathrm{CN}$ & D & DN \\
\hline LVSD (cm) & $0.54 \pm 0.02$ & $0.56 \pm 0.01$ & $0.46 \pm 0.02$ & $0.51 \pm 0.01$ \\
\hline LVDD (cm) & $0.87 \pm 0.02$ & $0.87 \pm 0.01$ & $0.77 \pm 0.02^{\star}$ & $0.83 \pm 0.02$ \\
\hline IVSD (cm) & $0.147 \pm 0.03$ & $0.152 \pm 0.002$ & $0.145 \pm 0.006$ & $0.125 \pm 0.003$ \\
\hline PWD (cm) & $0.150 \pm 0.003$ & $0.158 \pm 0.003$ & $0.148 \pm 0.06$ & $0.126 \pm 0.003$ \\
\hline RWT (cm) & $0.35 \pm 0.02$ & $0.36 \pm 0.01$ & $0.39 \pm 0.02$ & $0.31 \pm 0.01$ \\
\hline EF (\%) & $76 \pm 1$ & $74 \pm 1$ & $79 \pm 2$ & $76 \pm 2$ \\
\hline FS (\%) & $46.2 \pm 7.7$ & $44.6 \pm 8.6$ & $40.6 \pm 1.6$ & $45.9 \pm 7.9$ \\
\hline IVRT (ms) & $33.2 \pm 0.8$ & $29.4 \pm 1.2$ & $45.1 \pm 1.8^{\star}$ & $36 \pm 1.6^{\#}$ \\
\hline$E^{\prime}(\mathrm{ms})$ & $0.046 \pm 0.003$ & $0.045 \pm 0.002$ & $0.044 \pm 0.001$ & $0.042 \pm 0.002$ \\
\hline$A^{\prime}(\mathrm{ms})$ & $0.037 \pm 0.004$ & $0.031 \pm 0.001$ & $0.048 \pm 0.004$ & $0.051 \pm 0.004$ \\
\hline E/IVRT & $0.021 \pm 0.002$ & $0.028 \pm 0.002$ & $0.013 \pm 0.001^{\star}$ & $0.018 \pm 0.001^{\#}$ \\
\hline \multicolumn{5}{|c|}{$\begin{array}{l}\text { LVSD (left ventricle diameter in systole), LVDD (left ventricle diameter in diastole), IVSD } \\
\text { (interventricular septum in diastole), PWD (posterior wall in diastole), RWT (relative wall thickness), EF } \\
\text { (ejection fraction), FS (fractional shortening), IVRT (isovolumetric relaxation time), E' (early diastolic } \\
\text { mitral annular tissue velocity), A' (late atrial diastolic mitral annular velocity, E/IVRT (ratio between } \\
\text { early diastolic transmitral flow velocity and isovolumetric relaxation time). }{ }^{*} p<0.05 \text { vs. C; }{ }^{\#} p<0.05 \text { vs } \\
\text { D. }\end{array}$} \\
\hline
\end{tabular}

\section{Survival curve}

Mortality among studied rats was evaluated for 5 weeks. Our results showed that nicotinamide was an effective intervention to increase survival rate in STZ-induced diabetic rats. Figure 4 depicts the survival curve for all studied groups.

\section{Correlation analysis}

Pearson's correlation analysis using all diabetic rats showed strong associations between the index of reflex bradycardia and fasting glycemia

$(r=0.75, p=0.003)$, and the rate constant for plasma glucose disappearance $(k I T T)(r=-0.75, p=0.003)$. In addition, RMSSD was also associated with $\mathrm{kITT}(r=0.61, p=0.04)$. Moreover, body weight gain was associated with both bradycardia and tachycardia indexes with $(r=0.66, p=0.013 ; r=0.59, p=0.03$, respectively), as well as with $\mathrm{kITT}(r=0.78, p=0.001)$ and $\operatorname{RMSSD}(r=0.58, p=0.03)$.

\section{Discussion}


Our results confirmed that a single dose of nicotinamide before diabetes induction by STZ can attenuate most of the severe alterations observed in this diabetes model. The main novelty reported by the present study is that this protective effect of $\mathrm{N}$ was associated with preserved baroreflex sensitivity and parasympathetic modulation. The improvement in these autonomic parameters reflected in better metabolic profile, as observed in the correlation analyses results, and increased survival rate in diabetic rats that received nicotinamide when compared to rats that received only STZ.

It is well known that STZ is a potent cytotoxic drug to pancreatic beta-cells in rats. Briefly, STZ causes DNA damage of insulin-secreting cells, and this injury leads to mechanisms of DNA repair, mitochondria dysfunction and ATP depletion [31, 32]. As a result, rats present severe diabetes symptoms, similar to what was observed in our STZ animals, as exacerbated levels of glycemia and body weight loss. On the other hand, N protects pancreatic beta-cells from DNA damage; therefore, it blunts the development of several STZ-induced diabetes characteristics, as increased hyperglycemia and body weight loss.

In fact, hyperglycemia above $400 \mathrm{mg} / \mathrm{dl}$ is usually observed in STZ-induced diabetic rats [19,33-35] and it is associated with high mortality $[28,36]$. However, in the present study, nicotinamide-induced protective effects seemed to be independent of glycemia levels, as DN rats still showed high glycemia values ( $400 \mathrm{mg} / \mathrm{dl}$ ) despite being lower than $\mathrm{D}$ rats. Therefore, we investigated other factors which could mediate the improvements observed in DN rats.

It is well known that autonomic dysfunction is in the genesis and progression of several diseases. Parasympathetic dysfunction was associated with insulin resistance in fructose-fed rats [22]. Indeed, D rats presented insulin resistance evidenced by kITT, and this parameter was totally normalized in DN. Moreover, parasympathetic dysfunction and reflex mechanisms impairments in STZ-induced diabetic rats have already been reported $[19,33,36,37]$. This impairment may be a result of alterations in both the efferent limb of the reflex arc, and the central nervous system [38].

Baroreflex sensitivity impairment in the STZ model of diabetes has also been described [15, 28, 29, 36]. In our study, only the bradycardic response was impaired. This corroborates with the autonomic modulation profile of the studied rats, as in diabetic rats parasympathetic modulation was reduced. Even though DN rats were still hyperglycemic, glycemia was about $20 \%$ lower than D rats. De Angelis et al (2002) demonstrated that a better glycemic control is related to baroreflex sensitivity and autonomic improvements [38].

Accordingly, we found important associations between insulin resistance evaluated by kITT and RMSSD, a time-domain index of cardiac parasympathetic modulation. Also, kITT was associated with the index of reflex bradycardia, showing the interaction between insulin resistance and reflex control of blood pressure. Mechanisms underlying this association are not fully understood; however, some studies have demonstrated that improvements in cardiac oxidative stress profile may contribute to an optimal baroreflex sensitivity and insulin action in aged rats [39, 40]. 
STZ-induced diabetic rats also presented hemodynamic alterations which are closely related to autonomic dysfunction. Resting bradycardia and blood pressure decrease is a frequent observation [28, $36,37,41]$. Mostarda et al (2009) showed that resting bradycardia in diabetic rats occurs due to decreased intrinsic heart rate, while decreased blood pressure is linked to a reduction in cardiac output [28].

Cardiac function in STZ-induced diabetic may also be impaired, as systolic and diastolic dysfunctions have been described [27, 42]. Indeed, D rats had decreased IVRT and E/IVRT ratio, indicating diastolic dysfunction. We did not find systolic dysfunction or expressive morphological abnormalities; however, our follow-up period was shorter than other studies.

Diabetes patients present high levels of mortality mainly due to cardiovascular [1] complications. In asymptomatic individuals, it was observed that up to $20 \%$ of them presented impairment of cardiovascular autonomic function [43]. This information highlights the importance of neuropathy in the time course of diabetic disease.

Another characteristic of diabetes is body weight loss. In our study, rats that received $\mathrm{N}$ were able to maintain body weight stable throughout the studied period, while, as expected, diabetic rats had a severe weight loss (> 40\%). Guo et. al. (2019) reported that $\mathrm{N}$ had a protective effect on skeletal muscle atrophy in STZ-induced diabetic mice, which may be through inhibition of TGF-b1/Smad2 pathway [44]. Preservation of body mass seems to be an important feature in diabetes. The correlation analyses showed that diabetic rats with preserved body weight mass presented increased baroreflex sensitivity, increased RMSSD, and decreased insulin resistance.

Altogether, the improvements induced by nicotinamide in diabetic rats resulted in increased survival rate. In 13 weeks, survival in STZ-induced diabetic rats was approximately 50\% [28]. In our study, D rats survival rate in 5 weeks was $70 \%$, while DN rats presented $100 \%$ survival rate in the same period. Indeed, nicotinamide in addition to intensive insulin therapy during 2 years after type 1 DM diagnosis may improve metabolic control [45]. In contrast, 12 weeks supplementation of dietary nicotinamide riboside did not improve insulin sensitivity and other metabolic parameters in obese insulin resistance men [46]. Our new data showing improvement of autonomic modulation and in mortality in nicotinamide-treated animals may indicate a protective action that should be tested in long-term studies.

Diabetes induced by STZ and N remains stable for a long time and thus this model of diabetes is suitable not only for short-term but also for long-term studies. Moreover, this model is very useful in investigations of different aspects of diabetes, including diabetic complications and anti-diabetic properties of new drugs and natural compounds [47].

\section{Conclusion}

Nicotinamide associated with STZ is a more stable model of experimental diabetes by preventing STZinduced baroreflex impairment, parasympathetic dysfunction and insulin resistance in rats, independently 
of glycemia levels. In association with improved metabolic profile, and preserved body weight mass, these protective effects of nicotinamide resulted in increased survival rate.

\section{Abbreviations}

\begin{tabular}{|ll|}
\hline ADA: & American Diabetes Association \\
\hline C: & Control \\
\hline CN: & Control Nicotinamide \\
\hline D: & Diabetes \\
\hline DM: & Diabetes Mellitus \\
\hline DN: & Diabetes Nicotinamide \\
\hline DNA: & Deoxyribonucleic acid \\
\hline HF: & High Frequency \\
\hline HRV: & Heart Rate Variability \\
\hline IVRT: & Isovolumetric Relaxation Time \\
\hline kITT: & Rate Constant for Insulin Tolerance Test \\
\hline LF: & Low Frequency \\
\hline N: & Nicotinamide \\
\hline STZ: & Streptozotocin \\
\hline TGF: & Tumor Growth Factor \\
\hline SAPV: & Systolic Arterial Pressure Variability \\
\hline
\end{tabular}

\section{Declarations}

\section{Authors' contributions}

Authors' contributions: PLC, ICMS, EGC, CMCS and MCl conceived and designed the study. ICMS, AAR and $\mathrm{MCl}$ performed statistical analyses, discussed the data, and drafted the manuscript. MDTM analyzed echocardiogram data. PLC, MB and JFM performed the experiments. CMCS contributed with data analyses and interpretation. FS carried out the autonomic nervous system analyses. All authors reviewed and approved the final version of the manuscript.

\section{Acknowledgements}

Not applicable. 
Competing interests

The authors declare that they have no competing interests.

Availability of data and materials

Not applicable

Consent for publication

All authors have declared their consent for this publication.

Ethics approval and consent to participate

Not applicable.

Funding

This work was supported by Fundação de Amparo a Pesquisa do Estado de São Paulo (FAPESP 2012/20262-7) and Conselho Nacional de Pesquisa (CNPq 307138/2015-1), Brazil.

\section{References}

1. Association A: Classification and diagnosis of diabetes.Diabetes care 2017, 40:S11-S24.

2. Chen C, Cohrs CM, Stertmann J, Bozsak R, Speier S: Human beta cell mass and function in diabetes: recent advances in knowledge and technologies to understand disease pathogenesis.Molecular metabolism 2017, 6:943-957.

3. Barcala Tabarrozzi AE, Castro CN, Dewey R, Sogayar M, Labriola L, Perone MJ: Cell-based interventions to halt autoimmunity in type 1 diabetes mellitus.Clinical \& Experimental Immunology 2013, 171:135-146.

4. Hansen JB, Arkhammar G, Per O, Bodvarsdottir TB, Wahl P: Inhibition of insulin secretion as a new drug target in the treatment of metabolic disorders. Current medicinal chemistry 2004, 11:1595-1615.

5. Lencioni C, Lupi R, Del Prato S: Beta-cell failure in type 2 diabetes mellitus.Curr Diab Rep 2008, 8:179184.

6. Andreassi MG: Metabolic syndrome, diabetes and atherosclerosis: influence of gene-environment interaction.Mutation Research/Fundamental and Molecular Mechanisms of Mutagenesis 2009, 667:35-43.

7. Roche HM, Phillips C, Gibney MJ: The metabolic syndrome: the crossroads of diet and genetics.Proceedings of the Nutrition Society 2005, 64:371-377.

8. Masiello P, Broca C, Gross R, Roye M, Manteghetti M, Hillaire-Buys D, Novelli M, Ribes G: Experimental NIDDM: development of a new model in adult rats administered streptozotocin and nicotinamide.Diabetes 1998, 47:224-229. 
9. Rees D, Alcolado J: Animal models of diabetes mellitus.Diabetic medicine 2005, 22:359-370.

10. Polo V, Saibene A, Pontiroli A: Nicotinamide improves insulin secretion and metabolic control in lean type 2 diabetic patients with secondary failure to sulphonylureas.Acta diabetologica 1998, 35:61-64.

11. Pontiroli A, Galli L: Duration of obesity is a risk factor for non-insulin-dependent diabetes mellitus, not for arterial hypertension or for hyperlipidaemia.Acta diabetologica 1998, 35:130-136.

12. Williams A, Ramsden D: Nicotinamide: a double edged sword.Parkinsonism \& related disorders 2005 , 11:413-420.

13. Angelis KD, Senador DD, Mostarda C, Irigoyen MC, Morris M: Sympathetic overactivity precedes metabolic dysfunction in a fructose model of glucose intolerance in mice.American Journal of Physiology-Regulatory, Integrative and Comparative Physiology 2012, 302:R950-R957.

14. Bernardes N, da Silva Dias D, Stoyell-Conti FF, de Oliveira Brito-Monzani J, Malfitano C, Caldini EG, Ulloa L, Llesuy SF, Irigoyen M-C, De Angelis K: Baroreflex impairment precedes cardiometabolic dysfunction in an experimental model of metabolic syndrome: role of inflammation and oxidative stress.Scientific reports 2018, 8:8578.

15. Lin M, Ai J, Harden SW, Huang C, Li L, Wurster RD, Cheng ZJ: Impairment of baroreflex control of heart rate and structural changes of cardiac ganglia in conscious streptozotocin (STZ)-induced diabetic mice.Autonomic Neuroscience 2010, 155:39-48.

16. Svensson MK, Lindmark S, Wiklund U, Rask P, Karlsson M, Myrin J, Kullberg J, Johansson L, Eriksson $\mathrm{JW}$ : Alterations in heart rate variability during everyday life are linked to insulin resistance. A role of dominating sympathetic over parasympathetic nerve activity? Cardiovascular diabetology 2016, 15:91.

17. Brahmanaidu P, Uddandrao VS, Sasikumar V, Naik RR, Pothani S, Begum MS, Rajeshkumar MP, Varatharaju C, Meriga B, Rameshreddy P: Reversal of endothelial dysfunction in aorta of streptozotocin-nicotinamide-induced type-2 diabetic rats by S-Allylcysteine.Molecular and cellular biochemistry 2017, 432:25-32.

18. Giribabu N, Roslan J, Rekha SS, Salleh N: Methanolic seed extract of Vitis vinifera ameliorates oxidative stress, inflammation and ATPase dysfunction in infarcted and non-infarcted heart of streptozotocin-nicotinamide induced male diabetic rats. International journal of cardiology 2016, 222:850-865.

19. Mostarda C, Rogow A, Silva ICM, Raquel N, Jorge L, Rodrigues B, Heeren MV, Caldini EG, De Angelis K, Irigoyen MC: Benefits of exercise training in diabetic rats persist after three weeks of detraining.Autonomic neuroscience 2009, 145:11-16.

20. Moraes-Silva IC, Mostarda C, Moreira ED, Silva KAS, dos Santos F, De Angelis K, Farah VdMA, Irigoyen MC: Preventive role of exercise training in autonomic, hemodynamic, and metabolic parameters in rats under high risk of metabolic syndrome development.Journal of applied physiology 2013, 114:786-791.

21. Novelli E, Diniz Y, Galhardi C, Ebaid G, Rodrigues H, Mani F, Fernandes AAH, Cicogna AC, Novelli Filho $\mathrm{J}$ : Anthropometrical parameters and markers of obesity in rats.Laboratory animals 2007, 41:111-119. 
22. Brito J, Ponciano K, Figueroa D, Bernardes N, Sanches I, Irigoyen M, De Angelis K: Parasympathetic dysfunction is associated with insulin resistance in fructose-fed female rats.Brazilian Journal of Medical and Biological Research 2008, 41:804-808.

23. Conti FF, Brito JdO, Bernardes N, Dias DdS, Malfitano C, Morris M, Llesuy SF, Irigoyen M-C, De Angelis $\mathrm{K}$ : Positive effect of combined exercise training in a model of metabolic syndrome and menopause: autonomic, inflammatory, and oxidative stress evaluations.American Journal of PhysiologyRegulatory, Integrative and Comparative Physiology 2015, 309:R1532-R1539.

24. Furuya D, Binsack R, Machado U: Low ethanol consumption increases insulin sensitivity in Wistar rats.Brazilian Journal of Medical and Biological Research 2003, 36:125-130.

25. Bonoro E, Moghetti P, Zancanaro C, Cigolini M, Querena M, Cacciatori V, Corgnati A, Muggeo M:

Estimates of in vivo insulin action in man: comparison of insulin tolerance tests with euglycemic and hyperglycemic glucose clamp studies. The Journal of Clinical Endocrinology \& Metabolism 1989, 68:374-378.

26. Rodrigues B, Mostarda CT, Jorge L, Barboza CA, Grans CF, De Angelis K, Irigoyen MC: Impact of myocardial infarction on cardiac autonomic function in diabetic rats. Journal of Diabetes and its Complications 2013, 27:16-22.

27. Wichi R, Malfitano C, Rosa K, De Souza SB, Salemi V, Mostarda C, De Angelis K, Irigoyen MC: Noninvasive and invasive evaluation of cardiac dysfunction in experimental diabetes in rodents.Cardiovascular diabetology 2007, 6:14.

28. Mostarda C, Rodrigues B, Vane M, Moreira ED, Rosa K, Moraes-Silva IC, Lacchini S, Casarini DE, De Angelis K, Irigoyen MC: Autonomic impairment after myocardial infarction: role in cardiac remodelling and mortality.Clinical and Experimental Pharmacology and Physiology 2010, 37:447452.

29. Jorge L, Rodrigues B, Rosa KT, Malfitano C, Loureiro TCA, Medeiros A, Curi R, Brum PC, Lacchini S, Montano N: Cardiac and peripheral adjustments induced by early exercise training intervention were associated with autonomic improvement in infarcted rats: role in functional capacity and mortality. European heart journal 2010, 32:904-912.

30. dos Santos F, Moraes-Silva IC, Moreira ED, Irigoyen M-C: The role of the baroreflex and parasympathetic nervous system in fructose-induced cardiac and metabolic alterations.Scientific reports 2018, 8:10970.

31. Bedoya F, Solano F, Lucas M: N-monomethyl-arginine and nicotinamide prevent streptozotocininduced double strand DNA break formation in pancreatic rat islets. Experientia 1996, 52:344-347.

32. LeDoux S, Woodley S, Patton N, Wilson G: Mechanisms of nitrosourea-induced $\beta$-cell damage: alterations in DNA.Diabetes 1986, 35:866-872.

33. Dall'Ago P, Schaan BDA, da Silva VOK, Werner J, da Silva Soares PP, de Angelis K, Irigoyen MC: Parasympathetic dysfunction is associated with baroreflex and chemoreflex impairment in streptozotocin-induced diabetes in rats.Autonomic Neuroscience 2007, 131:28-35. 
34. Dall'Ago P, Silva V, De Angelis K, Irigoyen M, Fazan Jr R, Salgado H: Reflex control of arterial pressure and heart rate in short-term streptozotocin diabetic rats.Brazilian Journal of Medical and Biological Research 2002, 35:843-849.

35. Rodrigues B, Rosa KT, Medeiros A, Schaan BD, Brum PC, De Angelis K, Irigoyen MC: Hyperglycemia can delay left ventricular dysfunction but not autonomic damage after myocardial infarction in rodents.Cardiovascular diabetology 2011, 10:26.

36. Souza SB, Flues K, Paulini J, Mostarda C, Rodrigues B, Souza LE, Irigoyen M-C, De Angelis K: Role of exercise training in cardiovascular autonomic dysfunction and mortality in diabetic ovariectomized rats. Hypertension 2007, 50:786-791.

37. Maeda C, Fernandes T, Timm H, Irigoyen M: Autonomic dysfunction in short-term experimental diabetes. Hypertension 1995, 26:1100-1104.

38. De Angelis K, Schaan B, Maeda C, Dall'Ago P, Wichi RB, Irigoyen MC: Cardiovascular control in experimental diabetes.Brazilian Journal of Medical and Biological Research 2002, 35:1091-1100.

39. da Palma RK, Moraes-Silva IC, da Silva Dias D, Shimojo GL, Conti FF, Bernardes N, Barboza CA, Sanches IC, da Rosa Araújo AS, Irigoyen M-C: Resistance or aerobic training decreases blood pressure and improves cardiovascular autonomic control and oxidative stress in hypertensive menopausal rats.Journal of Applied Physiology 2016, 121:1032-1038.

40. da Silva Dias D, Moraes-Silva IC, Bernardes N, de Oliveira Brito-Monzani J, Stoyell-Conti FF, Machi JF, Llesuy S, Irigoyen M-C, De Angelis K: Exercise training initiated at old stage of lifespan attenuates aging-and ovariectomy-induced cardiac and renal oxidative stress: Role of baroreflex.Experimental gerontology 2019, 124:110635.

41. Dos Santos L, Mello A, Antonio EL, Tucci PJF: Determination of myocardial infarction size in rats by echocardiography and tetrazolium staining: correlation, agreements, and simplifications.Brazilian Journal of Medical and Biological Research 2008, 41:199-201.

42. dos Santos Silva KA, da Silva Luiz R, Rampaso RR, de Abreu NP, Moreira ÉD, Mostarda CT, De Angelis $\mathrm{K}$, Teixeira VdPC, Irigoyen MC, Schor N: Previous exercise training has a beneficial effect on renal and cardiovascular function in a model of diabetes.PloS one 2012, 7:e48826.

43. Boulton AJ, Vinik Al, Arezzo JC, Bril V, Feldman EL, Freeman R, Malik RA, Maser RE, Sosenko JM, Ziegler D: Diabetic neuropathies: a statement by the American Diabetes Association.Diabetes care 2005, 28:956-962.

44. Guo S, Chen Q, Sun Y, Chen J: Nicotinamide protects against skeletal muscle atrophy in streptozotocin-induced diabetic mice.Archives of physiology and biochemistry 2019, 125:470-477.

45. Crinò A, Schiaffini R, Ciampalini P, Suraci M, Manfrini S, Visaiii N, Matteoli M, Patera P, Buzzetti R, Guglielmi C: A Two Year Observational Study of Nicotinamide and Intensive Insulin Therapy in Patients with Recent Onset Type I Diabetes Mellitus.Journal of Pediatric Endocrinology and Metabolism 2005, 18:749-754.

46. Dollerup OL, Christensen B, Svart M, Schmidt MS, Sulek K, Ringgaard S, Stødkilde-Jørgensen H, Møller N, Brenner C, Treebak JT: A randomized placebo-controlled clinical trial of nicotinamide 
riboside in obese men: safety, insulin-sensitivity, and lipid-mobilizing effects. The American journal of clinical nutrition 2018, 108:343-353.

47. Szkudelski T: Streptozotocin-nicotinamide-induced diabetes in the rat. Characteristics of the experimental model.Experimental biology and medicine 2012, 237:481-490.

\section{Figures}

$1 \mathrm{~A}$

Body weight

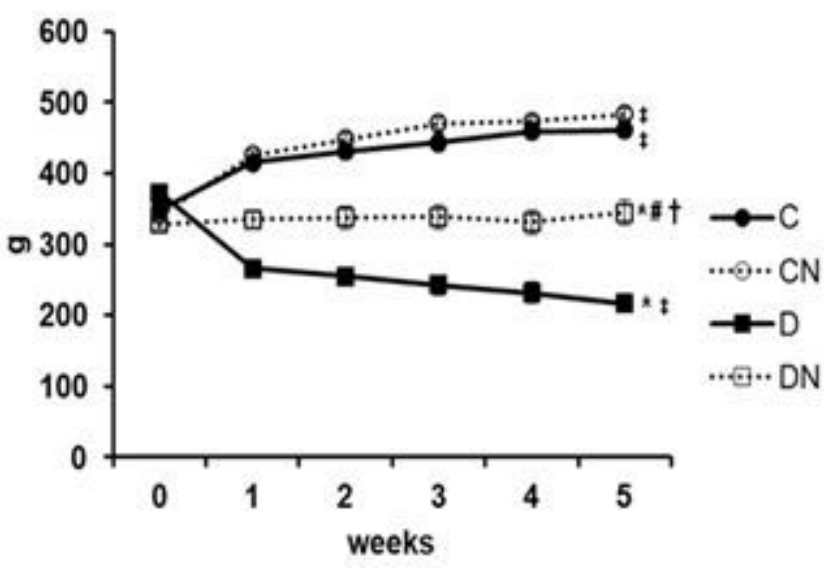

$1 \mathrm{~B}$

Lee index

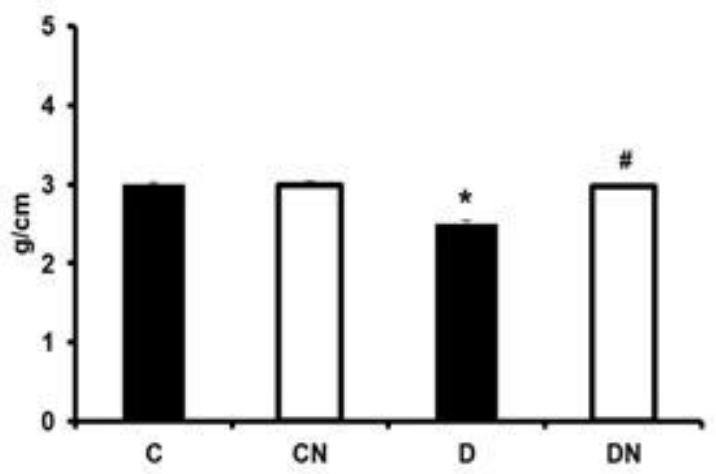

Figure 1

$1 \mathrm{~A}$, Body weight of control $(C, n=8)$; control nicotinamide $(C N, n=7)$; diabetes $(D, n=7)$ and diabetes nicotinamide (DN, $n=8)$ groups; ${ }^{*} p \leq 0.0001$ vs. $C ; \# p \leq 0.0001$ vs. $D ; \neq p \leq 0.0001$ vs. $C N ; \neq p \leq 0.0001$ week 5 vs. week 0 in the same group. 1B, Lee index of control rats $(C, n=8)$; control nicotinamide $(C N, n=7)$; diabetes ( $D, n=7)$ and diabetes nicotinamide (DN, $n=8) ;{ }^{*} p \leq 0.0001$ vs. $C ; \# p \leq 0.0001$ vs. $D$. 

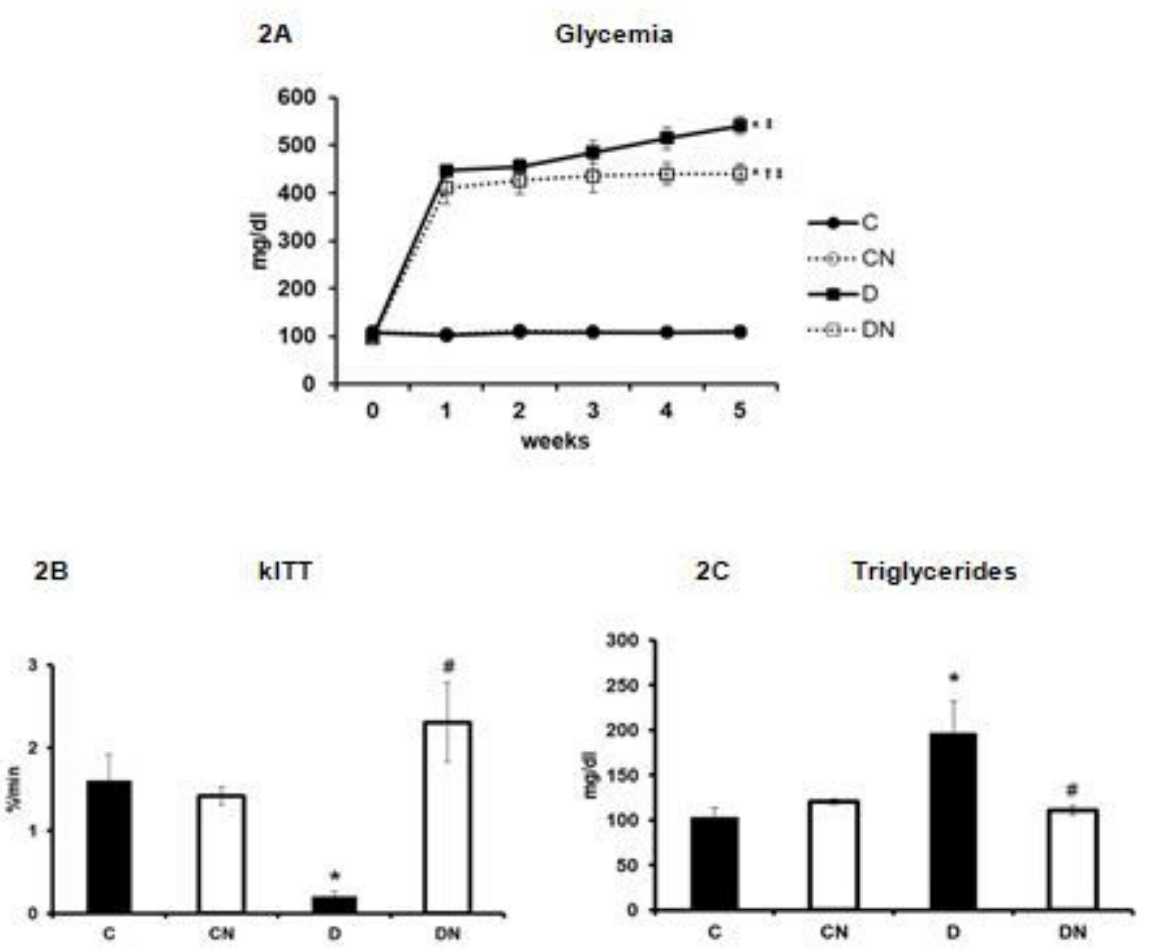

Figure 2

$2 A$, Fasting glycemia of control $(C, n=8)$; control nicotinamide $(C N, n=7)$; diabetes $(D, n=7)$ and diabetes nicotinamide ( $D N, n=8$ ) groups; ${ }^{\star} p \leq 0.0001$ vs. $C ; \uparrow p \leq 0.0001$ vs. $C N ; \neq p \leq 0.0001$ week 5 vs. week 0 in the same group. $2 \mathrm{~B}$, Insulin tolerance test evaluated by the constant decrease for plasma glucose (kITT) of control rats $(C, n=8)$ control nicotinamide $(C N, n=7)$; diabetes $(D, n=7)$ and diabetes nicotinamide (DN, $n=8) ;{ }^{*} \leq 0.0001$ vs. $C ; \# p \leq 0.0001$ vs. D. $2 C$, Fasting triglycerides levels of control rats $(C, n=8)$; control nicotinamide $(C N, n=7)$; diabetes $(D, n=7)$ and diabetes nicotinamide $(D N, n=8) ;{ }^{\star} p \leq 0.05$ vs. $C$; $\# p \leq 0.01$ vs. D. 


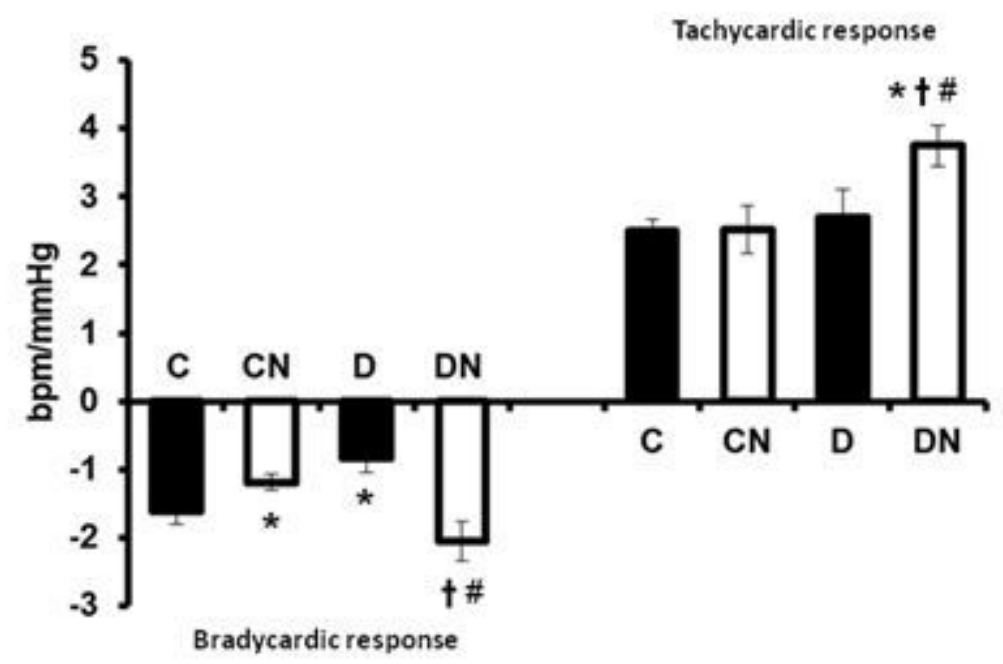

Figure 3

Baroreceptor reflex sensitivity evaluated by bradicardiac and tachycardic responses of control $(C, n=8)$; control nicotinamide $(C N, n=7)$; diabetes $(D, n=7)$ and diabetes nicotinamide $(D N, n=8)$ groups; ${ }^{\star} p \leq 0.05$ vs. $C ; \# p \leq 0.05$ vs. $D ;+p \leq 0.05$ vs. CN.

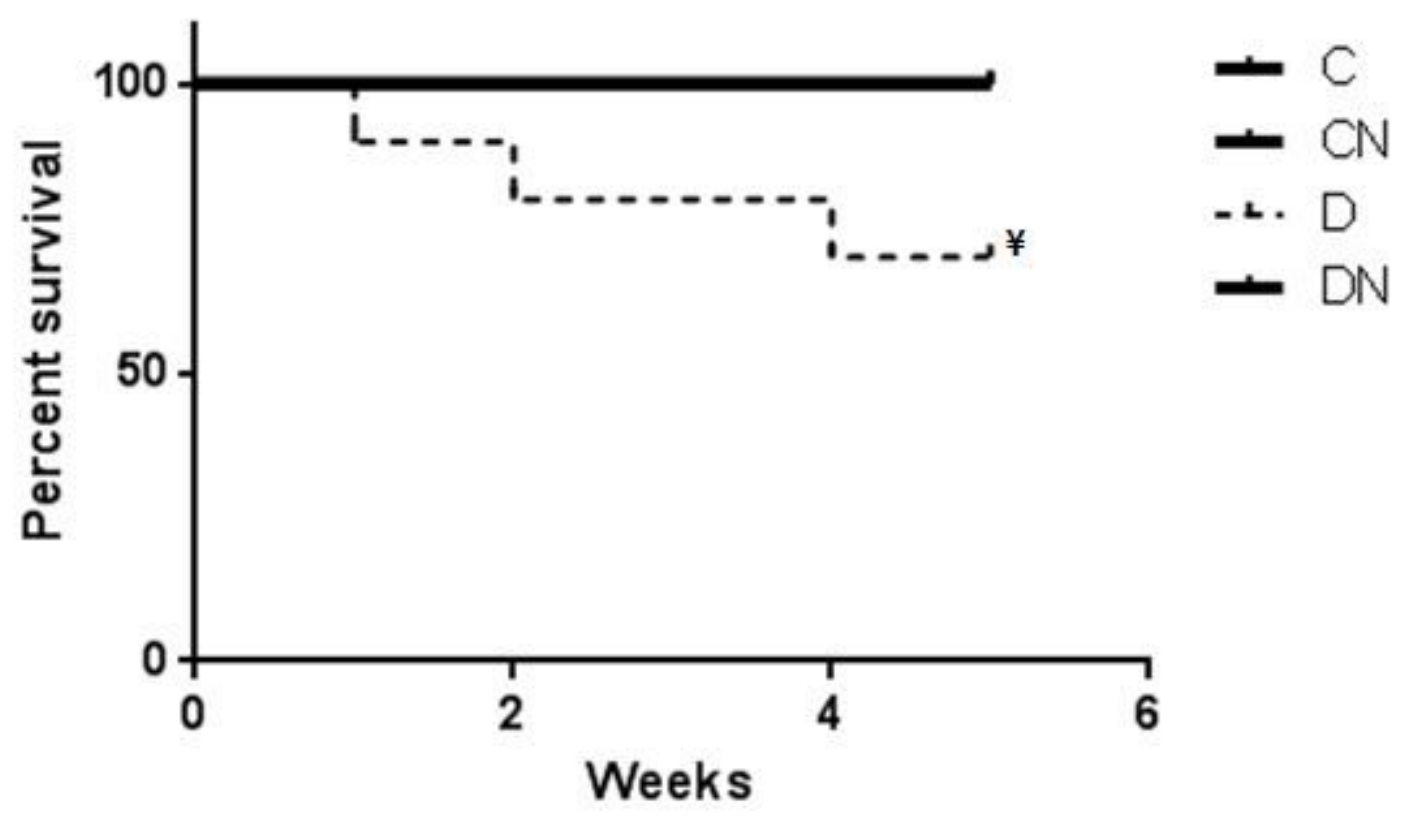

Figure 4

Survival percentage estimated by the Kaplan-Meier method of control $(C, n=8)$; control nicotinamide (CN, $n=7)$; diabetes $(D, n=7)$ and diabetes nicotinamide ( $D N, n=8)$ groups; $¥ \leq 0.05$ vs. all groups. 